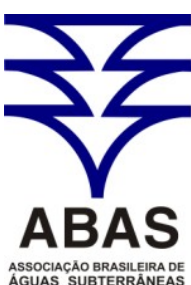

ASSOCIACAOB BRASLLERADE
AGUAS SUBTERRANEAS www.abas.org

\title{
ESTUDO DA VULNERABILIDADE À POLUIÇÃO DO AQUÍFERO MARIZAL NA REGIÃO DE INFLUÊNCIA DO POLO INDUSTRIAL DE CAMAÇARI (PIC) - BAHIA
}

\author{
STUDY OF THE MARIZAL AQUIFER VULNERABILITY TO \\ POLLUTON IN THE REGION OF INFLUENCE OF THE CAMAÇARI \\ INDUSTRIAL DISTRICT (PIC) - BAHIA
}

Paulo Roberto Penalva dos Santos; Iara Brandão de Oliveira

Artigo recebido em: 27/10/2011 e aceito para publicação em: 31/07/2012

\begin{abstract}
This study evaluated the Marizal aquifer vulnerability in the Camaçari Industrial District (PIC)'s region of influence using DRASTIC method and GIS. The studied region is located between two river basins: Joanes and Jacuípe, which present hydraulic connections with local aquifers. In this region the use of groundwater for multiple purposes (drinking and industry) has been growing in large scale and in a disorderly manner, especially in the urban areas, which may cause irreversible damages for local aquifers. Based on the properties involved on the DRASTIC method: geologic, hydrogeologic, topographic, soil, climate/recharge, it was possible to identify the vulnerable aquifer zones. The map of natural vulnerability of the Marizal aquifer showed that, $18.5 \%\left(44.1 \mathrm{~km}^{2}\right)$ of the studied area has low to very low vulnerability index, corresponding to the urban area of Camaçari city. Moderate vulnerability occurred on $61.7 \%\left(147.4 \mathrm{~km}^{2}\right)$ of the studied area, which is dedicated to industrial activities. The vulnerability ranging from high to extremely high occurred on $19.8 \%\left(47.5 \mathrm{~km}^{2}\right)$ of the remaining area, located in the northern region, which coincides with the discharge region of the unconfined aquifer underlying the PIC, and the urban area of Nova Dias D'Ávila.
\end{abstract}

Keywords: Vulnerability. Pollution. Aquifer. DRASTIC.

Resumo Foi avaliada a vulnerabilidade do aquífero Marizal, na região de influência do Polo Industrial de CamaçariBahia (PIC), utilizando o método DRASTIC em combinação com o Sistema de Informação Geográfica (SIG). A região estudada localiza-se entre as bacias hidrográficas dos rios Joanes e Jacuípe, que apresentam conexão hidráulica com os aquíferos locais. Na região, a utilização da água subterrânea para abastecimento humano e industrial vem crescendo de forma desordenada, principalmente nas áreas urbanas, podendo provocar prejuízos de caráter irreversível para os sistemas aquíferos locais. Com base nas características envolvidas no método: geológicas, hidrogeológicas, topográficas, solo, clima e recarga, o cálculo do índice DRASTIC permitiu identificar as zonas vulneráveis do aquífero. O mapa da vulnerabilidade natural do aquífero Marizal mostrou que, $18,5 \%\left(44,1 \mathrm{~km}^{2}\right)$ da área apresentam vulnerabilidade à poluição baixa a muito baixa, correspondendo à zona urbana de Camaçari. A vulnerabilidade moderada ocorreu na área destinada às atividades industriais, correspondendo a $61,7 \%\left(147,4 \mathrm{~km}^{2}\right)$ enquanto a vulnerabilidade variando de alta a extremamente alta, ocorreu em 19,8\% (47,5 $\left.\mathrm{km}^{2}\right)$ restantes da área, na porção norte da região de influência do PIC que coincide com a área de descarga do aquífero freático, subjacente ao PIC e a zona urbana de Nova Dias D’Ávila.

Palavras-Chave: Vulnerabilidade. Poluição. Aquífero Marizal. DRASTIC.

\section{INTRODUÇÃO}

Os primeiros a utilizar o conceito de vulnerabilidade de aquíferos à poluição foram Le Grand (1964), nos EUA, e Albinet \& Margat (1970), na França. Em suas primeiras avaliações sobre vulnerabilidade, Le Grand incorporou um sistema de pesos para avaliar o potencial de poluição das águas subterrâneas, considerando as características hidrogeológicas da área, a sensibilidade do aquífero com relação à natureza do contaminante e, as modificações de engenharia que pudessem reduzir o potencial de poluição intrínseca encontrado.

Na década de 1980, o conceito de vulnerabilidade dos aquíferos se difundiu, tendo sido elaborada a metodologia da agência ambiental americana (U-

\footnotetext{
${ }^{1}$ Geólogo (penalvapaulo@yahoo.com.br)

${ }^{2}$ Professora, Departamento de Engenharia Ambiental, Escola Politécnica, UFBA (oliveira@ufba.br)
} 
SEPA) em 1983, com base nas primeiras avaliações de vulnerabilidade de Le Grand e de outros autores (ALLER et al., 1987; FOSTER, 1987; FOSTER \& HIRATA, 1988).

$O$ conceito de vulnerabilidade assume diferentes significados (HIRATA, 2001), de vulnerabilidade intrínseca ou natural, estritamente associada às características naturais do aquífero, à vulnerabilidade mais ampla, por agregar uso e ocupação do solo, não sendo a vulnerabilidade uma propriedade absoluta, mas uma indicação relativa de áreas onde a contaminação tem maior probabilidade de ocorrer (NOBRE 2006). Para Nobre, o conceito de vulnerabilidade intrínseca ou natural está atrelado a três atributos importantes para determinar a capacidade de proteção natural do aquífero: (i) atenuação natural (processo natural de degradação de contaminantes presentes no solo e nas águas subterrâneas); (ii) recarga (entrada de água para o subsolo); (iii) transporte dos contaminantes no meio hidrogeológico. Ou seja, a vulnerabilidade é uma representação do grau de susceptibilidade do aquífero, frente a uma contaminação, e serve fundamentalmente para planejar o uso do solo com vistas à proteção dos aquíferos (WATERLOO, 2003).

Neste trabalho foi utilizado o método DRASTIC (ALLER et al., 1987) para avaliar a vulnerabilidade dos aquíferos à contaminação; ele utiliza sete parâmetros hidrogeológicos, cuja importância de cada um é definida através de pesos. Os parâmetros são identificados por cada uma das letras do acrônimo DRASTIC: D (Depth, peso 5) corresponde a profundidade do topo do aquífero em metro; $\mathbf{R}$ (Recharge, peso 4) corresponde a recarga do aquífero, em mm/ano; A (Aquifer material, peso 3) tipo de material do meio aquífero; $\mathbf{S}$ (Soil, peso 2) o tipo de solo; T (Topography, peso 1) a topografia; I (Influence of the unsaturated zone, peso 5) a influência da zona não saturada do solo; e, C (Conductivity, peso 3) corresponde à condutividade hidráulica do aquífero, em $\mathrm{cm} / \mathrm{seg}$. A cada parâmetro é associado um valor que varia de 1 a 10.

O índice DRASTIC é calculado para cada ponto da área de trabalho através da equação:

DRASTIC $=D_{i} x D_{p}+R_{i} x R_{p}+A_{i} x A_{p}+S_{i} x S_{p}+T_{i} x T_{p}+I_{i} x I_{p}+C_{i} x C_{p}$

Onde o sub-índice "i" refere-se ao parâmetro; e o sub-índice "p" ao peso do parâmetro.

Este trabalho avaliou a vulnerabilidade do aquífero Marizal, à poluição, na área do Polo Industrial de Camaçari (PIC), para delimitar e classificar as áreas onde o manancial hídrico deste aquífero tem maior ou menor grau de vulnerabilidade à poluição. Tendo em vista que o Marizal é um aquífero de transição e de recarga para o aquífero São Sebastião, manancial que deve ser preservado e protegido, pois é uma das fontes de abastecimento de água para toda a região, essa avaliação da vulnerabilidade torna-se muito importante e necessária nesta área.

\section{ÁREA DE ESTUDO}

O Polo Industrial de Camaçari está implantado na região metropolitana de Salvador, englobando parte dos municípios de Camaçari e de Dias D’Ávila (Figura 1).

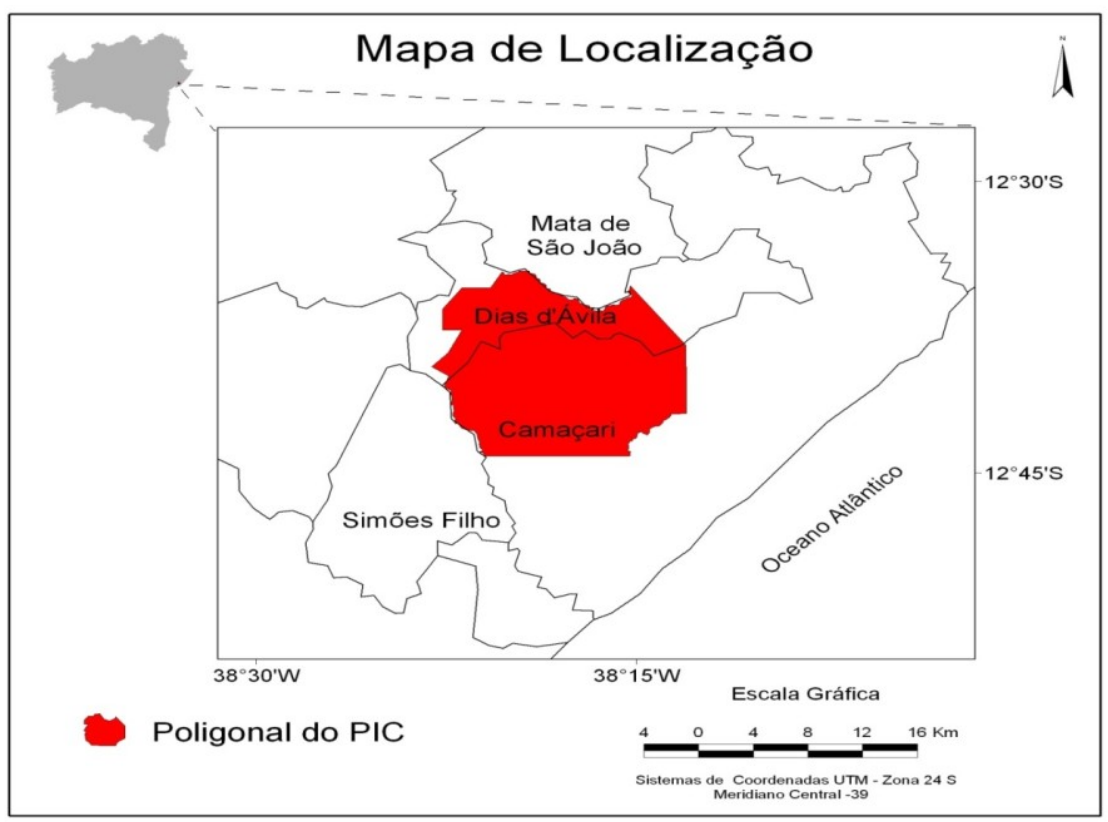

Figura 1- Mapa de localização da área de influência do Polo Industrial de Camaçari (PIC). 
O clima da região é quente e úmido, com chuvas concentradas no período de abril a junho, sendo o mês de maio o mais chuvoso e, o período seco ocorrendo entre outubro e março. Segundo a classificação de Köppen, o clima da área é do tipo $\mathrm{AF}$ (tropical chuvoso) com temperatura oscilando de $20^{\circ} \mathrm{C}$ a $30^{\circ} \mathrm{C}$, com mínimas registradas entre julho e agosto e as máximas, de março a dezembro.
A Figura 2 apresenta a rede hidrográfica da área, formada por três rios principais, Joanes, Jacuípe e Pojuca (RHAMA, 2009), mostrando que a área do Polo Industrial de Camaçari encontra-se no divisor de águas dos rios Joanes e Jacuípe.

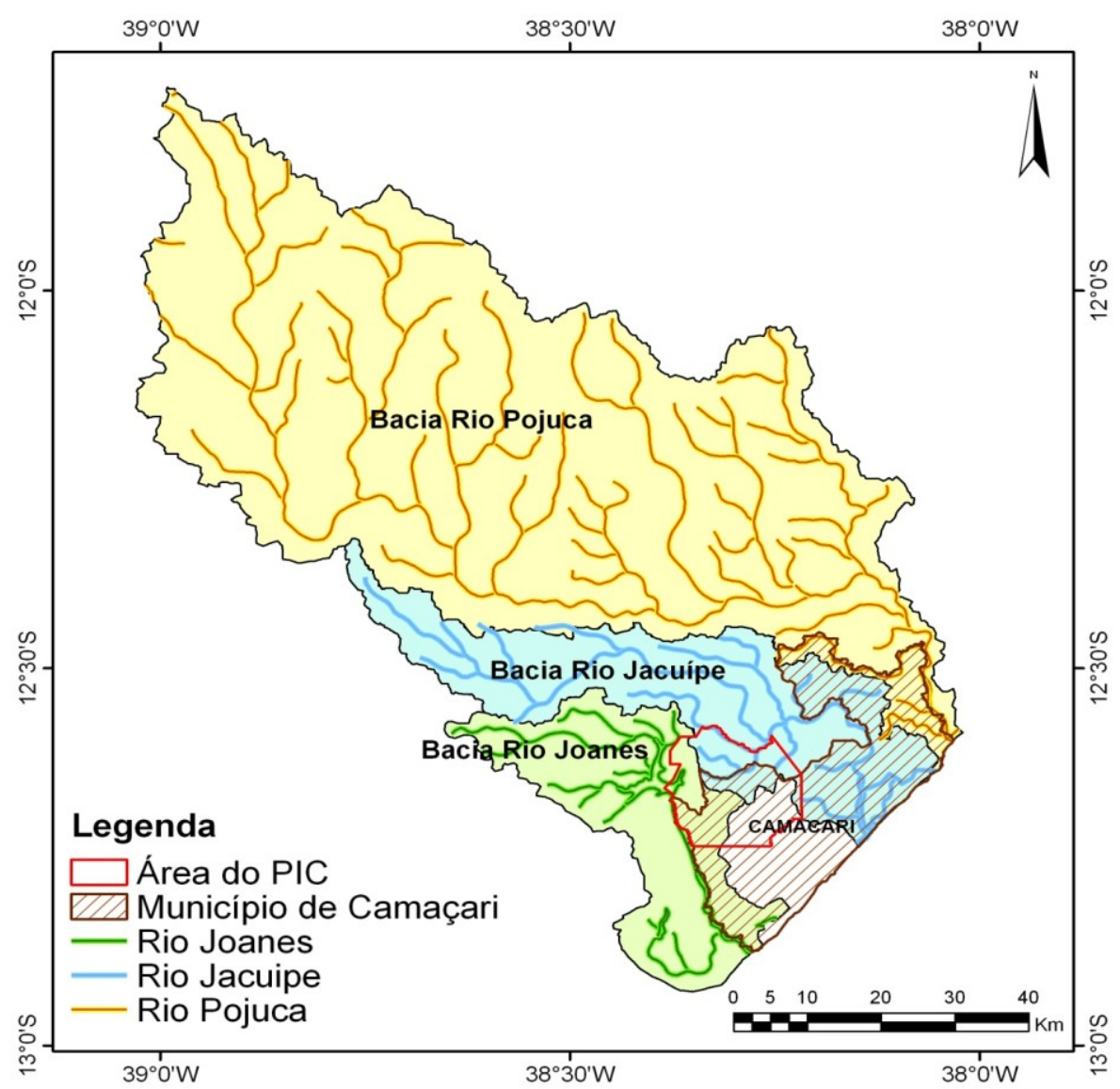

Figura 2 - Mapa das bacias hidrográficas dos rios Jacuípe, Joanes e Pojuca e entorno oficial da área do PIC (RHAMA 2009, modificado).

Os rios Joanes e Jacuípe apresentam conexão hidráulica com a água subterrânea do aquífero local, com fluxos variáveis e complexas relações de carga e descarga, estando o aquífero sujeito à influência das atividades do PIC e das cidades de Camaçari e Dias D’Ávila (SANTOS et al., 1998).
A Figura 3 apresenta o mapa do modelo digital do relevo da área de influência do PIC. 


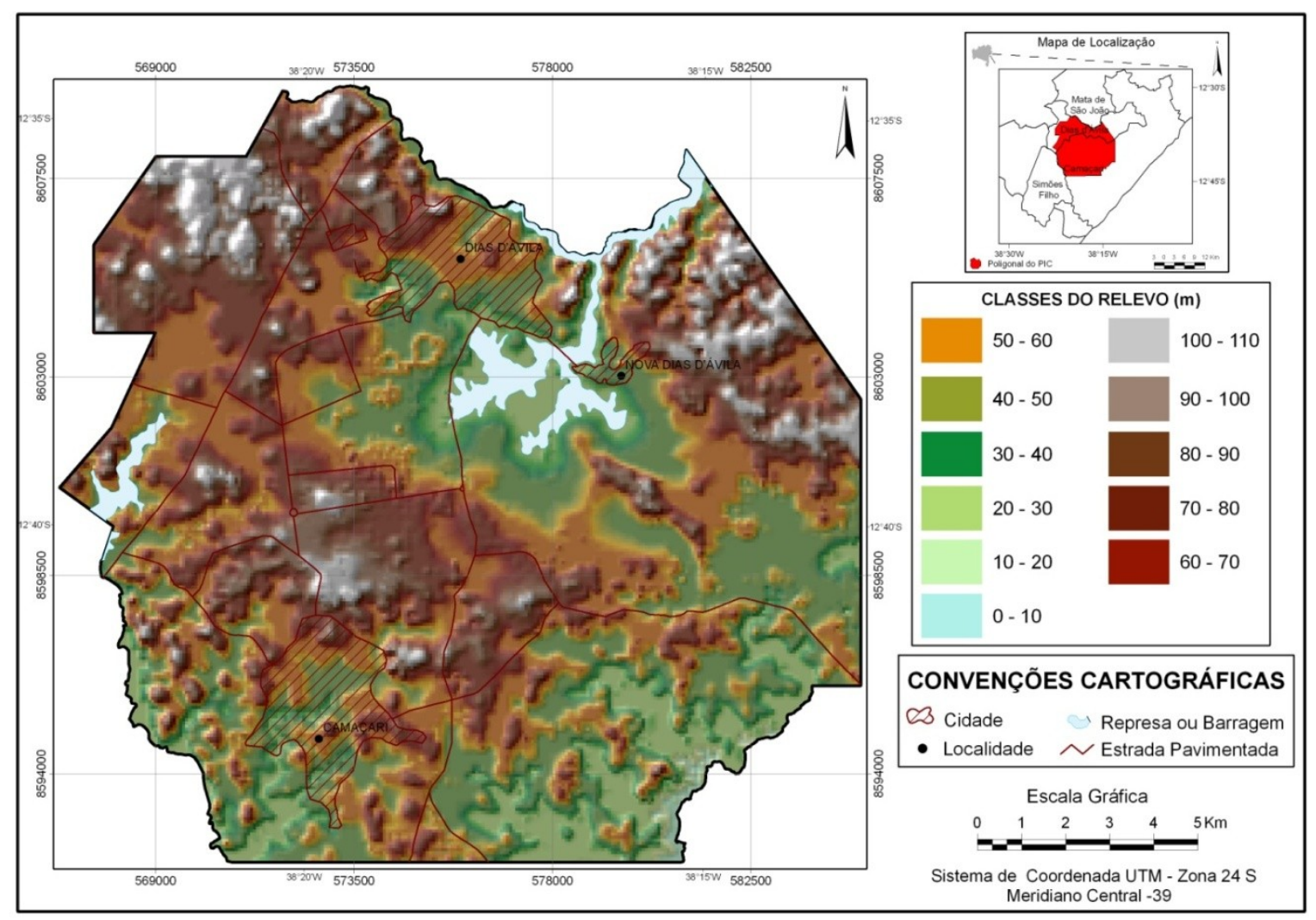

Figura 3 - Mapa do modelo digital do relevo da área de influência do PIC.

O relevo da região apresenta três tipos de modelados: aplainamento, acumulação e dissecação. As áreas mais elevadas sofreram dissecação e aplainamento e são formadas por solos residuais, constituídos de siltes arenosos e argilosos intercalados, de capacidade de uso variada e, de coloração rosada e branca. $\mathrm{O}$ transporte desses solos por águas pluviais desenvolveu depósitos superficiais de solos transportados que se acumularam na parte inferior dos morros, como: areia fina, pouco compacta, branca ou cinza; e, depósitos de argila siltosa, mole e turfosa, nos talvegues, ao longo dos riachos.
A Figura 04 apresenta o mapa de solos da área de influência do PIC. Segundo os estudos da Embrapa (2006) e de Stagliorio (2005), na região do PIC são encontrados solos dos tipos: Latossolos; Argissolos com texturas: arenosa, arenoargilosa e argilosa; Neossolos e Espodossolos Quartzarênicos; e, Argilossolos com textura arenoargiloso. O mapa mostra as áreas de ocorrência dos principais tipos de solos, com notada predominância dos Latossolos Vermelho Amarelo Distrófico, que têm boa fertilidade natural e, os solos Argissolos Vermelho Amarelo Distrófico, com baixa fertilidade natural. 


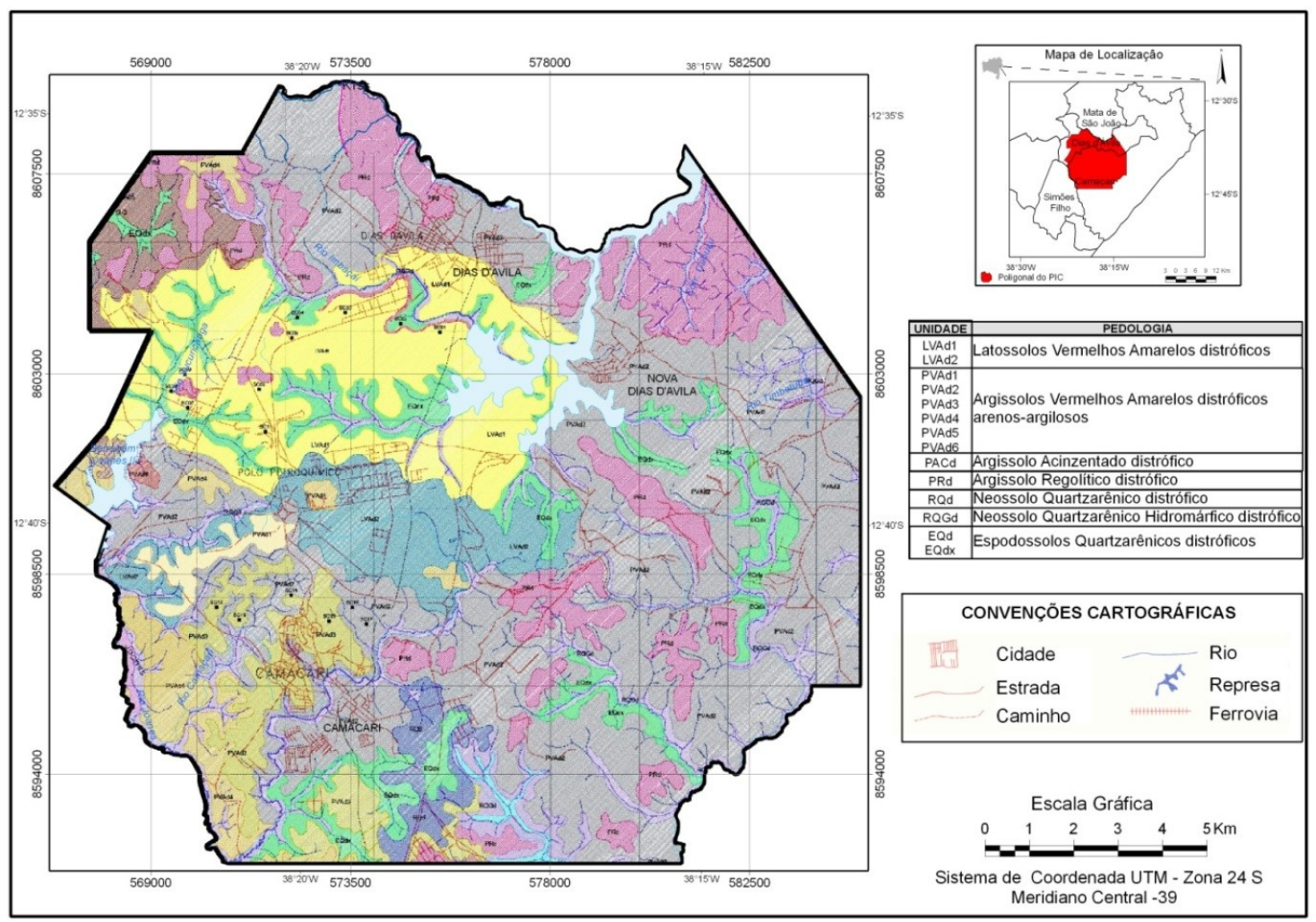

Figura 4 - Mapa de solos da região do PIC (STAGLIORIO 2005, adaptado).

A Figura 5 mostra o mapa de uso e ocupação do solo da área de influência do PIC.

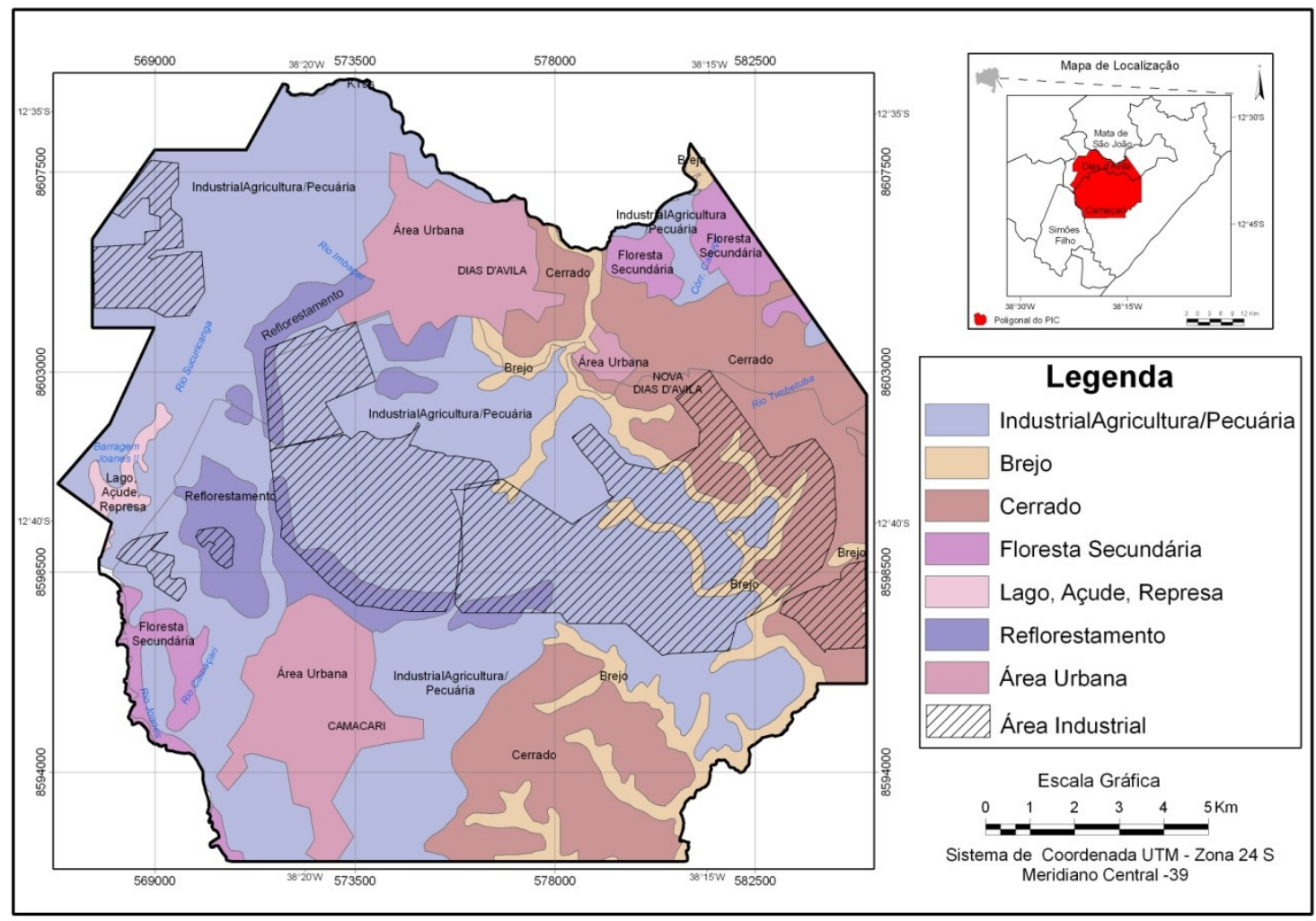

Figura 5 - Mapa de uso e ocupação do solo, ano 2005 (STAGLIORIO 2005, adaptado). 
O mapa de uso e ocupação do solo (Figura 5), mostra a grande área com atividade industrial do PIC e a área urbana na região de Camaçari, Dias D'Ávila e seu entorno, as quais se caracterizam como principais fontes de contaminação para as águas subterrâneas dessa região.

A Tabela 1 apresenta os percentuais de ocupação do solo. Embora, neste trabalho, não tenham sido mapeados, isoladamente, os usos e ocupação do solo, como exploração mineral e agricultura de subsistência, estes têm contribuído com alguma intensidade para a contaminação desses mananciais.

A Figura 6 mostra o mapa geológico simplificado da área de influência do PIC.

Tabela 1- Uso e ocupação do solo na área do PIC (STAGLIORIO 2005, adaptada).

\begin{tabular}{lcc}
\hline \multicolumn{1}{c}{ Tipo de ocupação } & Área $\mathbf{( k m}^{\mathbf{2}} \mathbf{)}$ & Área (\%) \\
\hline Indústria, Agricultura e Pecuária. & 123,1 & 51,4 \\
Área Urbana & 24,8 & 10,4 \\
Brejo & 17,2 & 7,2 \\
Cerrado & 48,4 & 20,2 \\
Floresta Secundária & 8,9 & 3,7 \\
Lago, Açude e Represa & 1,5 & 0,6 \\
Reflorestamento & 15,5 & 6,5 \\
\hline Total & 239,3 & 100 \\
\hline
\end{tabular}

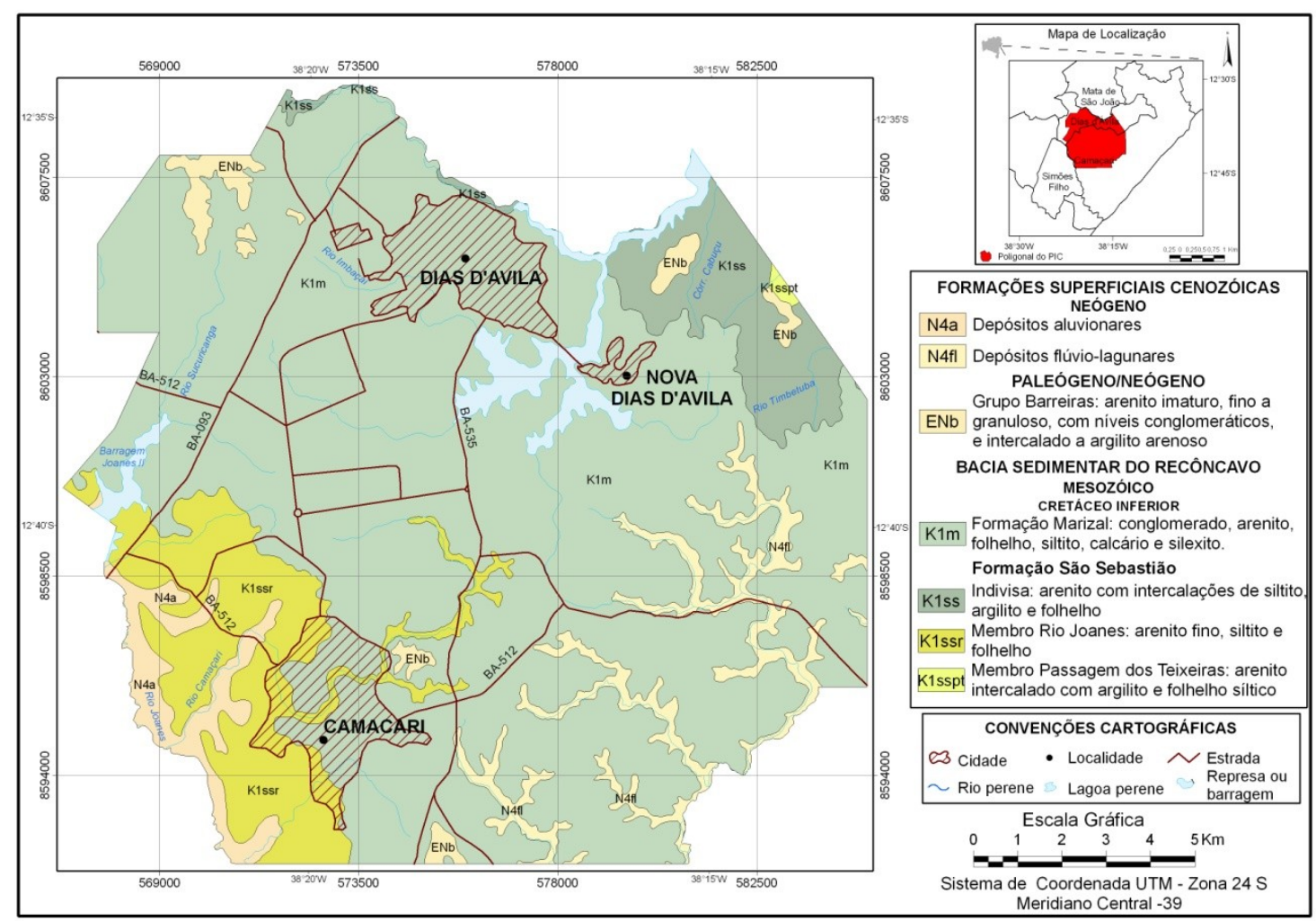

Figura 6 - Mapa geológico simplificado da área do PIC (CPRM 2008, adaptado) 
A área mostrada na Figura 6 está inserida nos domínios da Bacia Sedimentar do Recôncavo e integra o sistema "rift-valey". Essa bacia resultou do preenchimento de uma fossa tectônica por sedimentos continentais flúvio-lacustre, implantada sobre rochas pré-cambrianas do cráton São Francisco, constituindo o chamado Supergrupo Bahia, cuja espessura máxima atinge cerca de $6000 \mathrm{~m}$ (VIANA et al., 1971). Esses sedimentos apresentam uma grande variação faciológica e, está definida da base para o topo pelas Formações Aliança e Sergi (Grupo Brotas), Candeias e Itaparica (Grupo Santo Amaro), Grupo Ilhas (Indiviso, Formação Pojuca e Formação Marfim) e Formação São Sebastião. Essa última apresenta-se em multicamadas, e se constitui no melhor aquífero da região, denominado de Aquífero São Sebastião, que abastece anualmente $50 \%$ da demanda de água das empresas do PIC além das sedes municipais de Camaçari e Dias D'Ávila e comunidades circunvizinhas (SANTOS et al., 1998).

Sobreposto a essa sequência, em contato discordante, estão os sedimentos da Formação Marizal, com espessura média de 30 metros na área de estudo, depositada na fase pós-rift (CPRM, 2008). A Formação Marizal é caracterizada por um conglomerado basal e por arenitos variegados, argilitos e siltitos com espessura menor que $50 \mathrm{~m}$ na Bacia do Recôncavo. (VIANNA et al., 1971), depositados em ambiente de leques aluviais e sistemas fluviais entrelaçados (LIMA, 1991), com grandes variações faciológicas, tanto horizontal quanto vertical. A base da Formação é geralmente caracterizada pela ocorrência de conglomerados polimíticos. O PIC está implantado sobre os sedimentos da Formação Marizal, os quais se assentam sobre os sedimentos da Formação São Sebastião.

Posteriormente, foram depositados os sedimentos clásticos do Grupo Barreiras e os sedimentos aluvionares, de pântanos e mangues, fluvio-lagunares, de dunas, litorâneos holocênicos, litorâneos pleistocênicos, de leques aluviais coalescentes, detríticos lateríticos e sedimentos da Formação Sabiá, composta de folhelho com intercalações de arenito puro, calcário e arenito marinho.

Do ponto de vista hidráulico o aquífero Marizal é freático, principalmente na área de estudo e, constitui-se num meio extremamente heterogêneo, podendo apresentar localmente efeitos de confinamento devido à presença de níveis menos permeáveis (argilitos e folhelhos) além de ocorrência de aquíferos suspensos. A infiltração é a principal fonte de recarga das águas subterrâneas, segundo indicam estudos isotópicos realizados por Lima (1999) e Nascimento (1999), sendo as áreas de recarga situadas junto aos altos topográficos e as de descargas junto aos córregos, rios, drenos e áreas alagadas.

A Figura 7 apresenta o mapa potenciométrico do aquífero freático na região industrial do PIC, no verão de 2006, com profundidade de até 30 metros. Os dados de carga hidráulica foram medidos nos poços de monitoramento do Programa de Gerenciamento dos Recursos Hídricos do Polo (PGRH), obtidos do Banco de Dados da Cetrel.

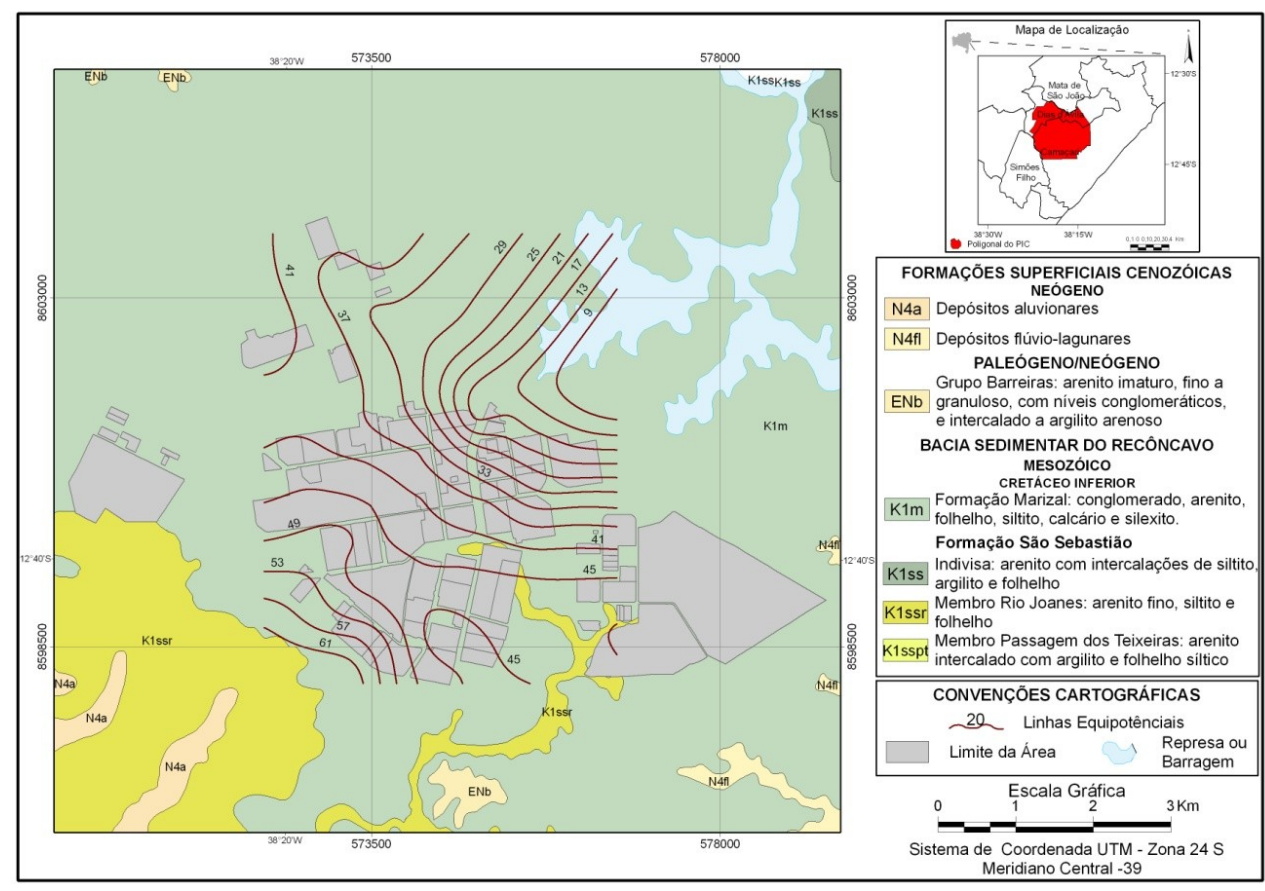

Figura 7 - Mapa potenciométrico do aquífero freático da região industrial do Polo Industrial de Camaçari, período verão, ano 2006, profundidade até 30 metros. 
Como mostrado na Figura 7, a direção do fluxo subterrâneo do aquífero Marizal, na região central do PIC, é SW - NE convergindo para o rio Imbassaí, afluente do rio Jacuípe, área mais próxima da descarga natural do aquífero. Ao Norte, o sentido do fluxo é NW-SE e na parte Leste é SE NW. Todos esses fluxos também convergem para o rio Imbassaí. Entretanto, as configurações da potenciometria do aquífero necessitam de maiores detalhamentos em algumas áreas, tanto em função da complexidade hidrogeológica, como da pouca densidade de poços, além de avaliações de possíveis fontes de recarga artificiais tais como linhas de adução de sistemas de abastecimento de água potável ou de efluentes ou de fossas sépticas.

\section{APLICAÇÃO DO MÉTODO DRASTIC NA ÁREA DE ESTUDO}

A Figura 8 apresenta a localização dos 580 poços utilizados no estudo, concentrados na área industrial do PIC.

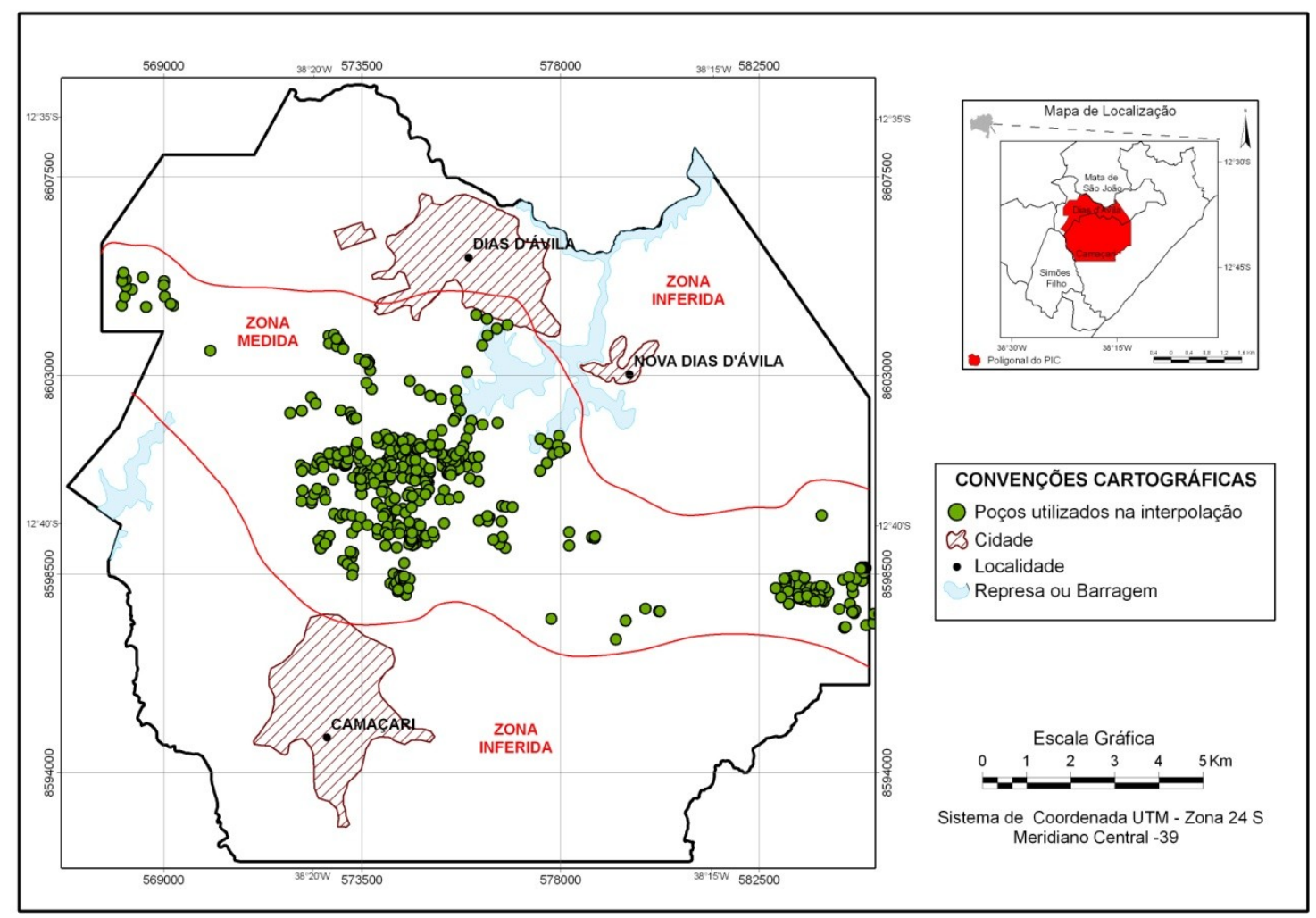

Figura 8 - Mapa de localização dos poços utilizados no estudo e áreas de domínio de dados medidos e inferidos.

Os poços estão localizados no domínio de dados medidos, denominada de "Zona Medida"; sendo as áreas sem poços, ou, domínio de dados inferidos, designada de "Zona Inferida". Na zona inferida, os dados foram extraídos dos mapas geológicos, topográficos e de visitas in loco, para identificar redes de drenagem, pontos de exudação do aquífero, entre outros aspectos geológicos.

Para gerar os dados necessários ao cálculo dos sete parâmetros do índice DRASTIC, foram utilizados dados e informações do Banco de Dados da Cetrel, em SIG (Sistema de Informações Geográficas), referentes aos poços do Programa de Gerenciamento dos Recursos Hídricos do Polo (PGRH), que inclui poços de monitoramento convencionais e poços multinível, além de relatórios, desenhos e registros operacionais. As propriedades hidráulicas do aquífero Marizal foram obtidas através de testes de aquífero do tipo slug test.

Os dados foram trabalhados utilizando o software MONITORxyzt (XYZtemas Consultoria, Salvador-BA, Versão 2,0) interligado ao SIG disponível na plataforma Microsoft SQL Server. Para a elaboração dos mapas temáticos, do mapa potenciométrico, geológico e de localização, utilizou-se os Softwares: ArcGIS (ESRI, USA, Versão 9.3), CorelDraw X3 (Corel Corporation, USA, Versão: 13.0), e Adobe Acrobat (Adobe Systems Incorporated and Licensors, USA, Versão: 8.0).

Os sete mapas temáticos, um para cada parâmetro do DRASTIC, foram sobrepostos para proceder a operação algébrica realizada através do ArcGIS para criar o Índice DRASTIC. A imagem (raster) foi convertida em arquivo vetorial (shape- 
file), para agrupar os temas, utilizando as classes de vulnerabilidade. Depois que as classes foram agrupadas e simplificadas, foi calculado a área para cada classe de vulnerabilidade.

\section{RESULTADOS E DISCUSSÃO}

São apresentados a seguir, todos os mapas temáticos para o aquífero Marizal, na área da Poligonal do Polo Industrial de Camaçari, um para cada parâmetro do DRASTIC.

A Figura 9 mostra o mapa de profundidade do nível estático com a distribuição areal de cada classe.

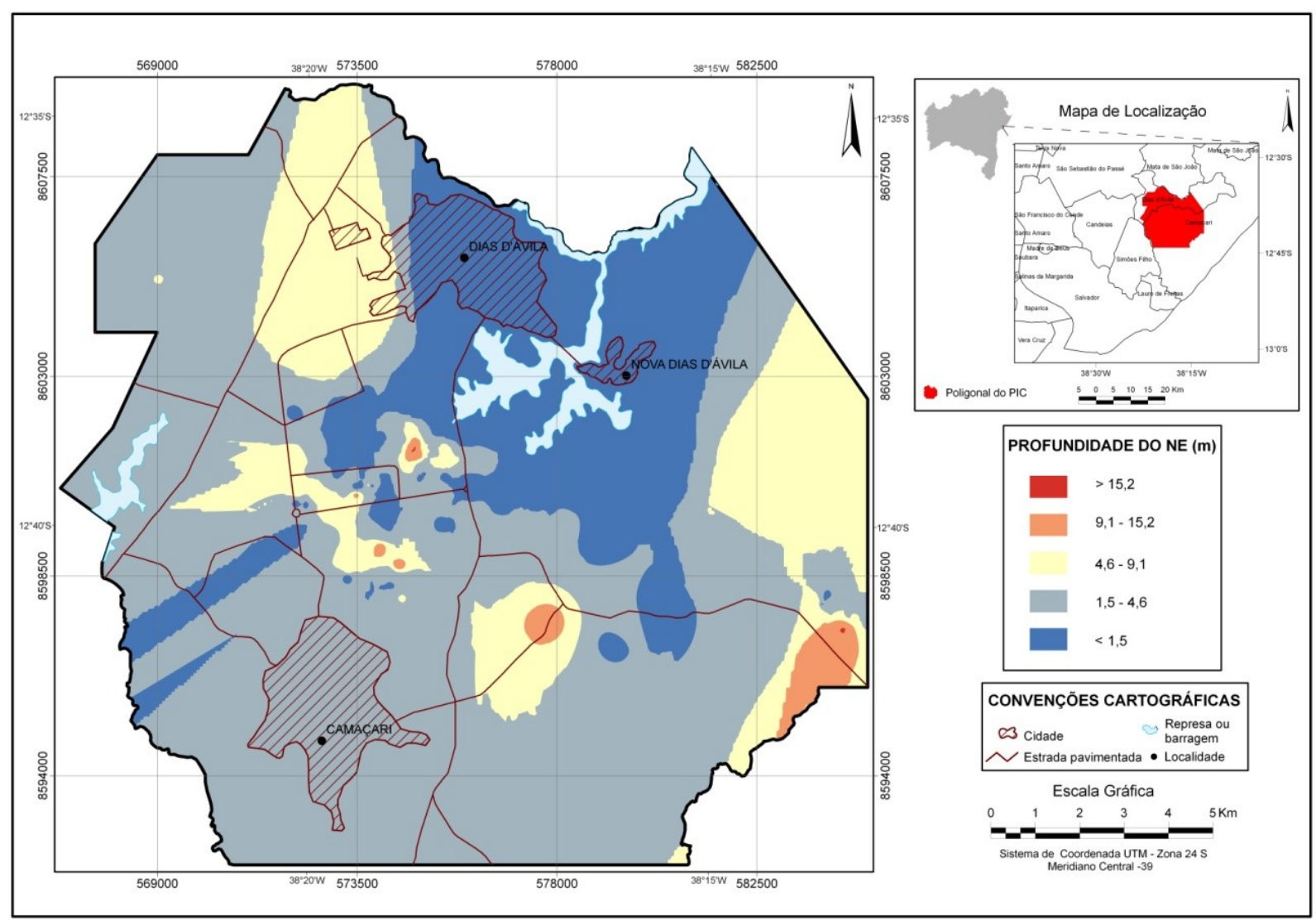

Figura 9 - Mapa de Profundidade do Nível Estático da Poligonal do PIC

Como se podem verificar, as áreas da classe de profundidade entre 1,5 a $4,6 \mathrm{~m}$ prevalecem sobre as demais $(56,6 \%)$, sendo a mais vulnerável; seguida da classe de profundidade inferior a $1,5 \mathrm{~m}$ com $24,1 \%$ da área total. A área que indica menos vulnerabilidade à poluição totaliza apenas 1,35\% da área do PIC e engloba as classes 9,1 a $15,2 \mathrm{~m}$ e > $15,2 \mathrm{~m}$ com porção sul e oeste do PIC.

A Figura 10 mostra o mapa de recarga da área do PIC, período de verão. 


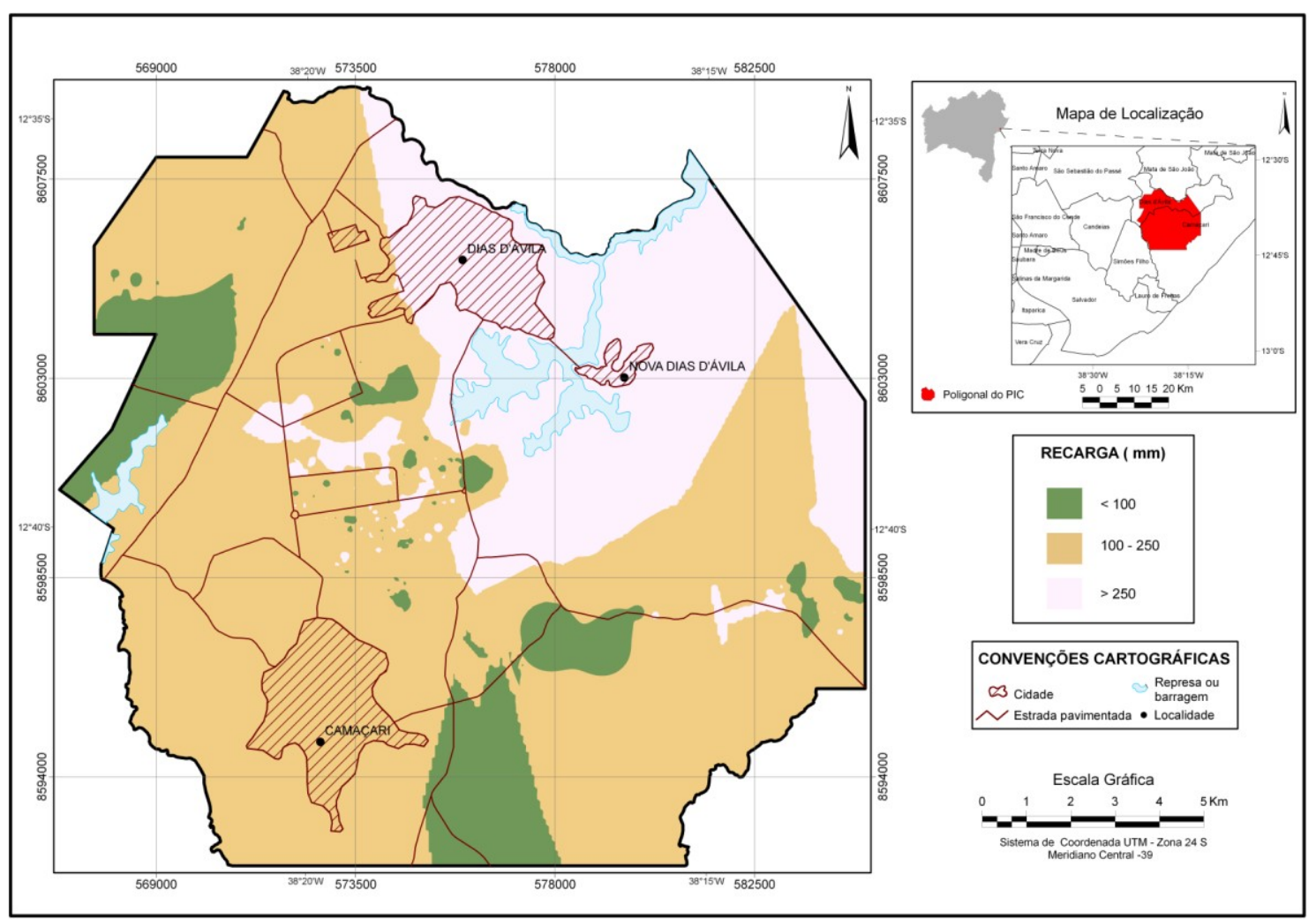

Figura 10 - Mapa de Recarga da Poligonal do PIC.

Três valores de recarga foram definidos: acima de $250 \mathrm{~mm} / \mathrm{ano}$, ocorrendo para as áreas localizadas em planícies de inundação, topograficamente baixas e com predominância de sedimentos arenosos; valores entre 100 e $250 \mathrm{~mm} / \mathrm{ano}$, para as áreas antropizadas, com elevada densidade de unidades industriais; e, menor que $100 \mathrm{~mm} / \mathrm{ano}$, para as áreas antropizadas, com alta densidade demográfica, com declividade e com impermeabilização do solo. Como se pode verificar a classe entre o intervalo de 100 e $250 \mathrm{~mm}$ prevalece sobre as demais, totalizando $63,2 \% \%$ da área total do PIC; seguindo-se a classe $>250 \mathrm{~mm}$, que ocupa área de $26,8 \%$, e representa a região mais vulnerá- vel, porque engloba a região de descarga do aquífero superficial. A área de menor recarga, é de apenas $10 \%$ e situa-se na porção sul e oeste do PIC.

A Figura 11 mostra a distribuição das várias classes do meio aquífero consideradas no estudo. Foram definidas quatro unidades litológicas: argilito/argila, silte e areia argilosa; arenitos com intercalações; e, areia/conglomerado. A classe do arenito com intercalações e a classe das areia conglomerática, representam $75,2 \%$ da área total do PIC. A classe silte e areia argilosa representam $24,8 \%$. 


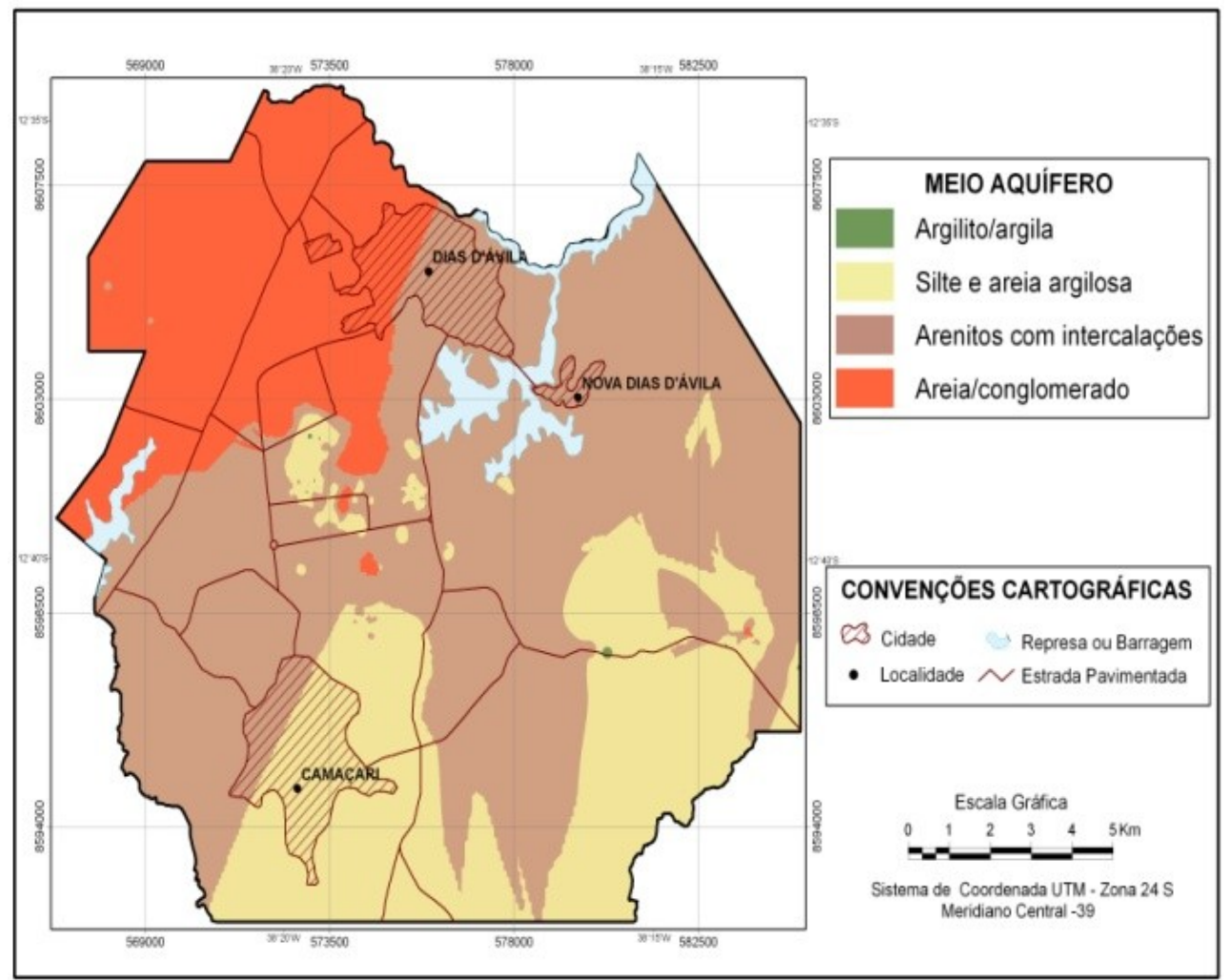

Figura 11- Mapa do Meio Aquífero da Poligonal do PIC

A Figura 12 mostra a distribuição das várias classes de solo consideradas no estudo. Das cinco classes de solo consideradas, até a profundidade de 1 metro, a classe do Latossolo representa $47,11 \%$ e, o Neossolo Espodossolo (17,3\%) as quais representam, respectivamente, as áreas mais vulneráveis da área total do PIC. Segue-se a classe dos Argilossolos com textura arenosa, com $34 \%$ da área. A classe menos vulnerável está representada pela classe Argilossolos com textura argilosa $(0,13 \%)$.

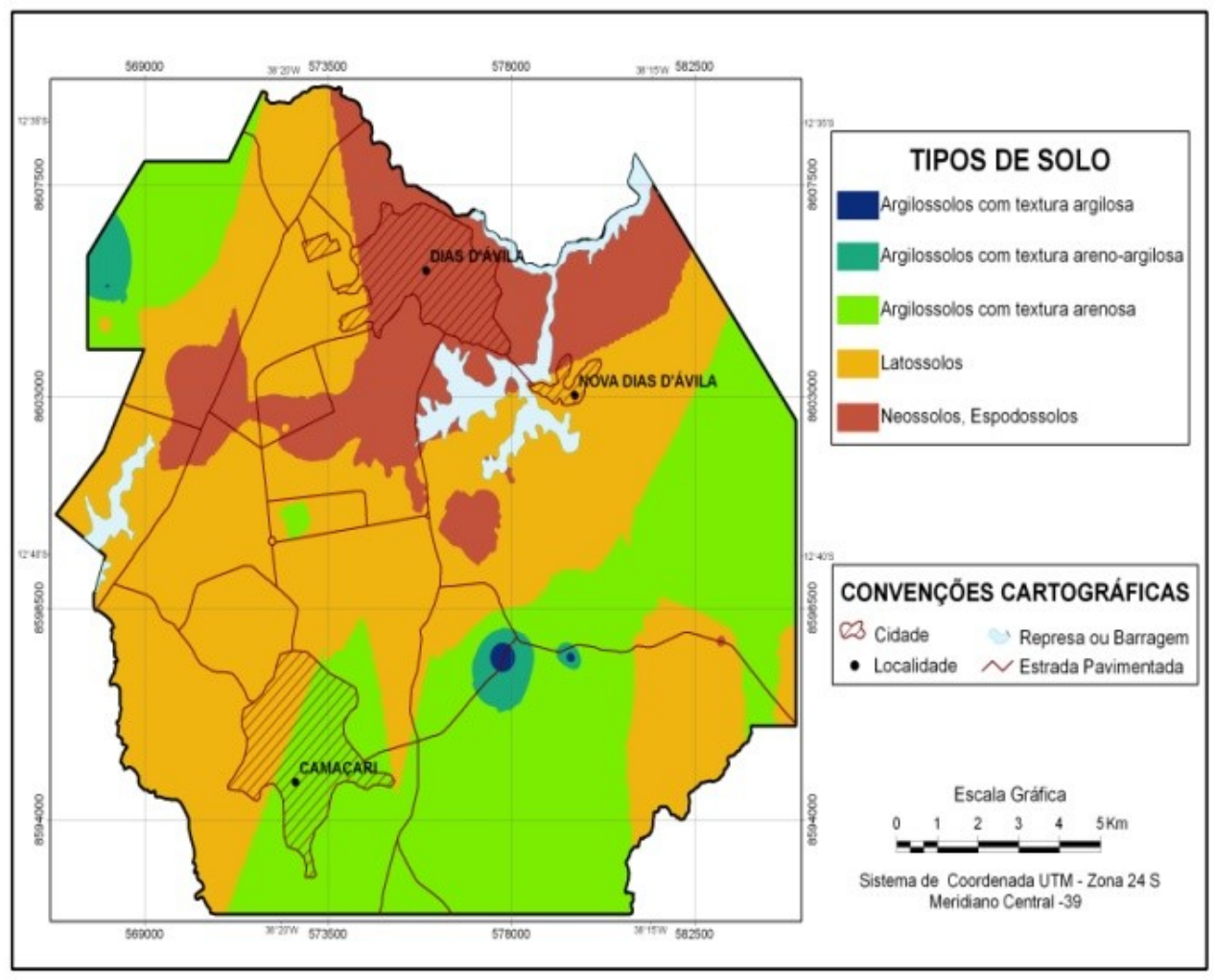

Figura 12 - Mapa dos tipos de Solo da Poligonal do PIC 
A Figura 13 ilustra o mapa de declividade da área de estudo.

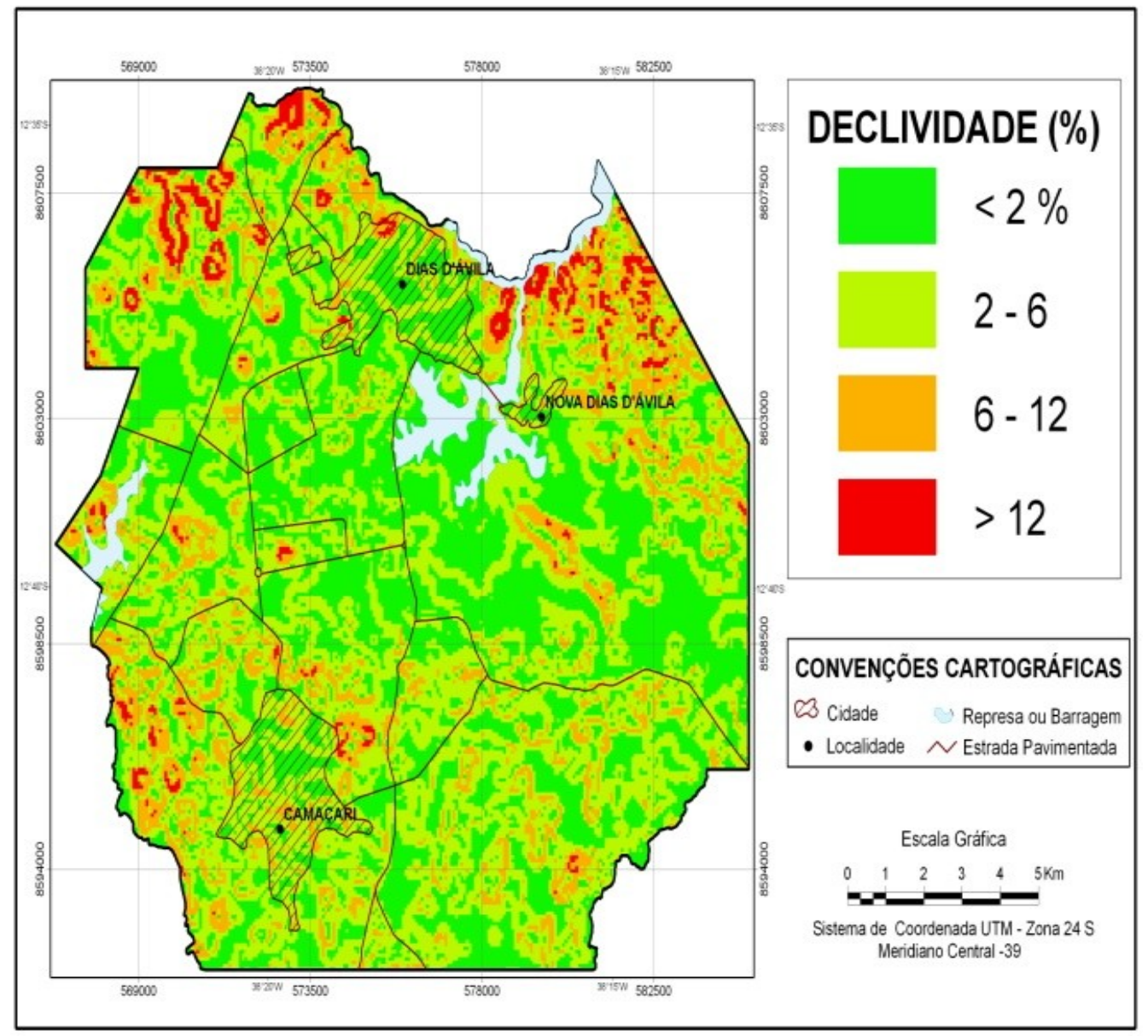

Figura 13- Mapa Topográfico (Declividade) da Poligonal do PIC

Verifica-se que grande parte da área apresenta declividade baixa, inferior a $6 \%(83,8 \%)$. As altas declividades localizadas nas áreas de encostas e vales dissecados dos tabuleiros circunscrevendo a área do PIC representam $16,4 \%$ da área total. As declividades mais suaves facilitam a infiltração e, portanto, oferecem maior risco de contaminação do aquífero. Por outro lado, as superfícies mais ín- gremes favorecem maior velocidade do escoamento superficial e, contribuem para maior erosão e contaminação de águas de superfície. De $0-2 \%$ de declividade existe um grande potencial de infiltração, acima de $12 \%$ diminui esse potencial.

A Figura 14 ilustra o mapa de influência da zona não saturada da área do PIC. 


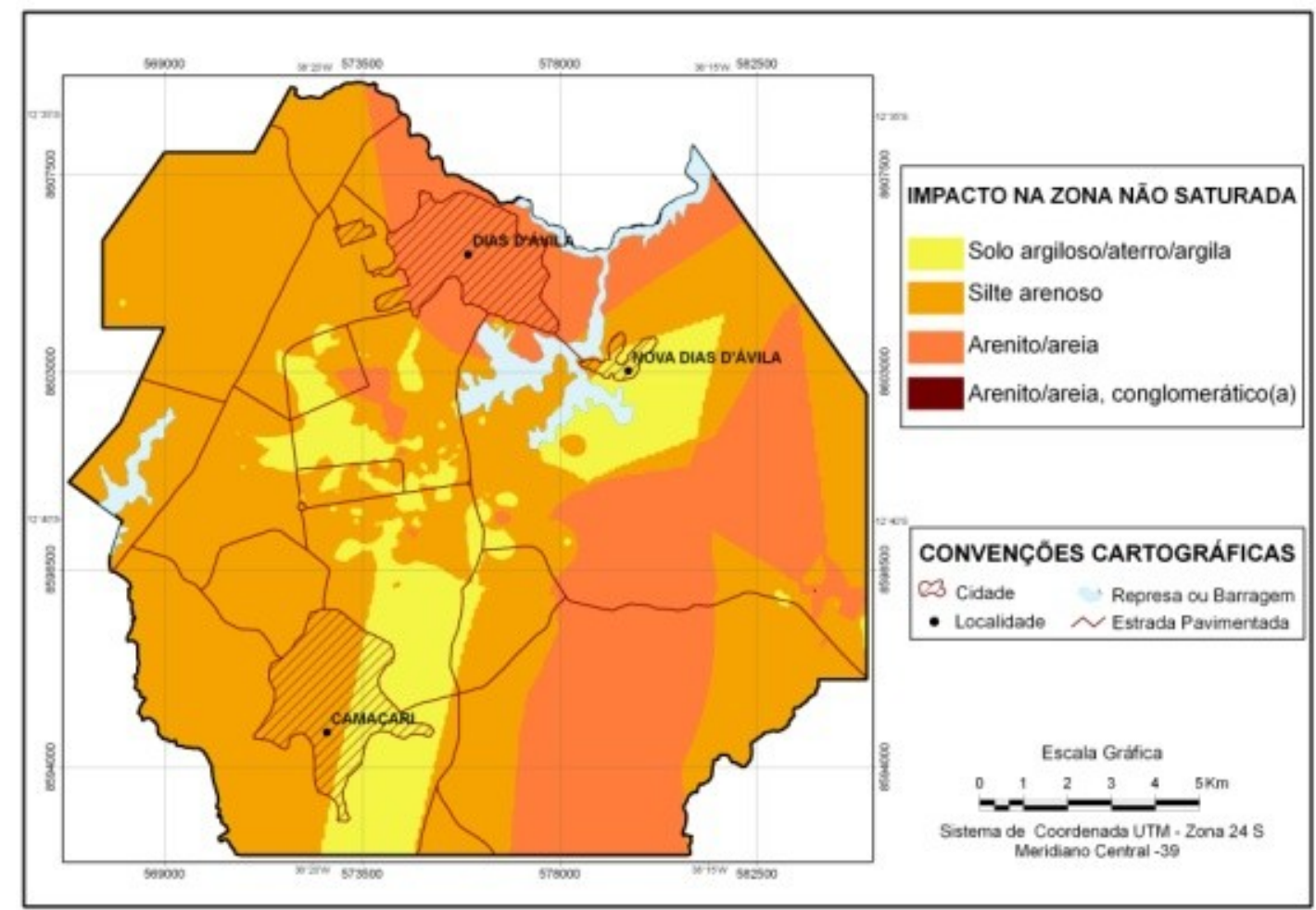

Figura 14 - Mapa de Influência da zona não saturada

Foram definidas quatro classes de material: i) solo argiloso/aterro/argila, ii) silte arenoso, iii) arenito/areia e, iv) arenito/areia, conglomerado. A classe silte arenoso representa o maior percentual de área $(58,77 \%)$ seguido pela classe arenito/areia, com $27,9 \%$ da área total.

A Figura 15 mostra o mapeamento das classes de condutividade hidráulica do aquífero Marizal na região do PIC. A condutividade hidráu- lica varia de $10^{-3}$ a $10^{-7} \mathrm{~cm} / \mathrm{s}$ evidenciando, um sistema deposicional bastante variado. Verificamse mudanças de até três ordens de grandeza na condutividade hidráulica em distâncias inferiores a 10 metros. Das cinco classes de condutividade hidráulica consideradas neste estudo, $70,67 \%$ corresponde ao intervalo entre $10^{-5}$ e $10^{-3} \mathrm{~cm} / \mathrm{s}$, prevalece sobre as demais. 


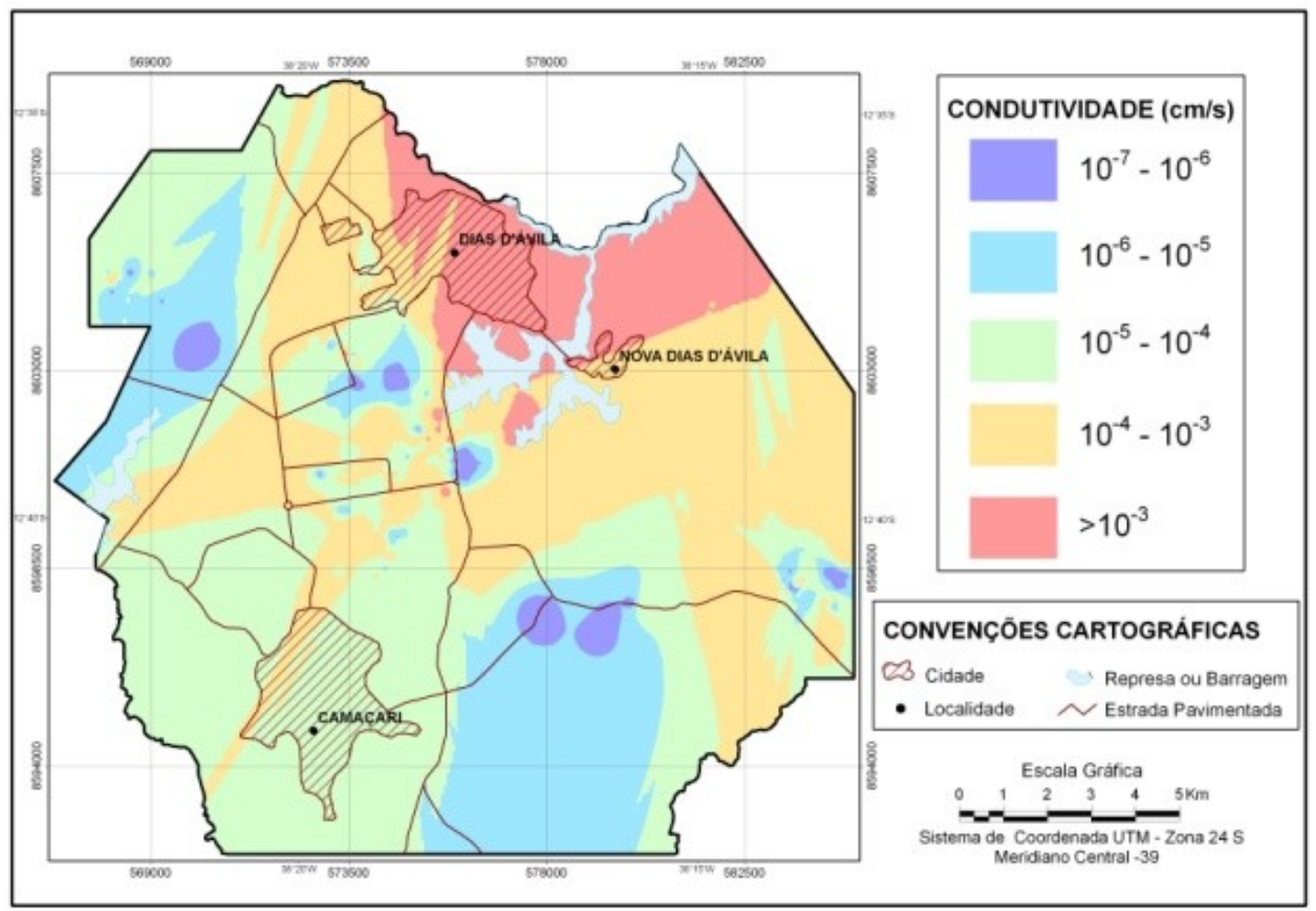

Figura 15 - Mapa de Condutividade Hidráulica da Poligonal do PIC

A Figura 16 apresenta o mapa de vulnerabilidade DRASTIC para o aquífero Marizal na área do PIC.

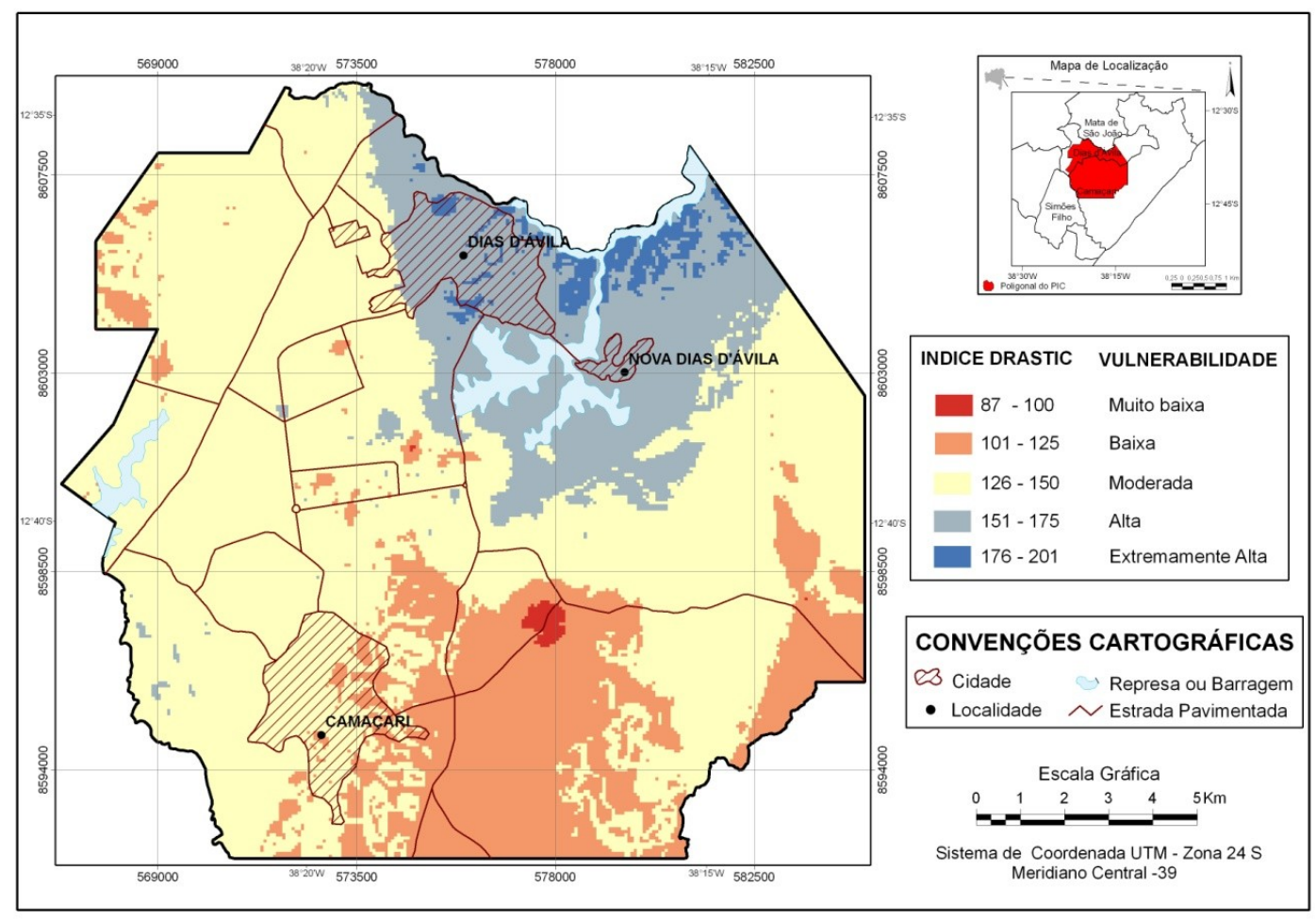

Figura 16 - Mapa de Vulnerabilidade DRASTIC da região do PIC, Período Verão de 2006. 
A Tabela 2 apresenta os valores do índice de vulnerabilidade, construída com base nas informações da Figura 16.

Tabela 2 - Índices de Vulnerabilidade, por classe.

\begin{tabular}{clcc}
\hline Índice DRASTIC & \multicolumn{1}{c}{ Vulnerabilidade } & $\begin{array}{c}\text { Área } \\
\mathbf{( k m}^{\mathbf{2}}\end{array}$ & $\begin{array}{c}\text { Área } \\
\mathbf{( \% )}\end{array}$ \\
\hline $87-100$ & Muito baixa & 0,7 & 0,3 \\
$101-125$ & Baixa & 43,4 & 18,2 \\
$126-150$ & Moderada & 147,4 & 61,7 \\
$151-175$ & Alta & 42,8 & 17,9 \\
$176-201$ & Extremamente alta & 4,7 & 2,0 \\
\hline
\end{tabular}

Os resultados mostram que somente $18,5 \%$ $\left(44,1 \mathrm{Km}^{2}\right)$ da área de influência do PIC apresenta vulnerabilidade de baixa a muito baixa, com índice DRASTIC de 87 a 125; a área de vulnerabilidade moderada à poluição foi encontrada em $61,7 \%$ $\left(147,4 \mathrm{Km}^{2}\right)$, com índice DRASTIC de 126 a 150. Enquanto o restante da área, $19,8 \%\left(47,5 \mathrm{Km}^{2}\right)$, apresenta vulnerabilidade de extremamente alta a alta, com índice de 151 a 201.

Nas regiões com vulnerabilidade modera$\mathrm{da}$, predominam as atividades industriais no uso $\mathrm{e}$ ocupação do solo. A região urbana da sede de $\mathrm{Ca}$ maçari está localizada em áreas de baixa vulnerabilidade; no entanto, devido à baixa densidade de poços de monitoramento, principalmente nesta área, esta avaliação fica limitada, sendo necessário maior número de dados para melhorar a representatividade e reduzir incertezas.

A região mais vulnerável onde ocorrem as áreas de alta a muito alta vulnerabilidade natural à poluição, e maiores índices DRASTIC, está localizada na porção norte, região da planície de inundação do rio Imbassaí, na área de descarga do aquífero freático subjacente ao PIC. A população da cidade de Nova Dias Ávila também está instalada nessa área.

A Figura 17 apresenta os sete mapas temáticos de cada parâmetro do Índice DRASTIC, juntamente com o mapa de vulnerabilidade DRASTIC, para auxiliar na visualização do grau de importância ou impacto de cada parâmetro sobre o cálculo da vulnerabilidade. 


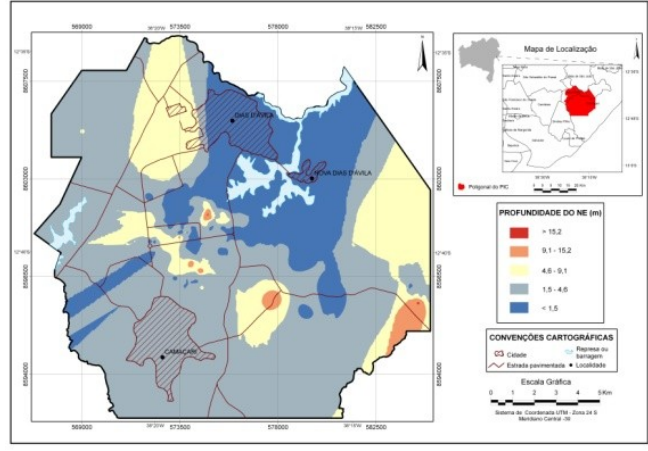

D: Profundidade do nível estático (PESO 5)

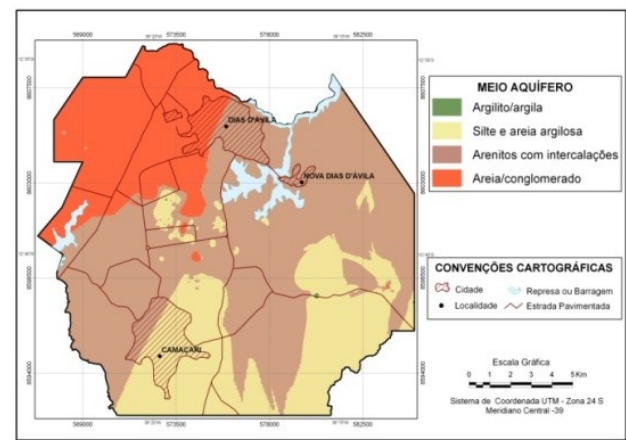

A: Material do meio aquífero (PESO 3)

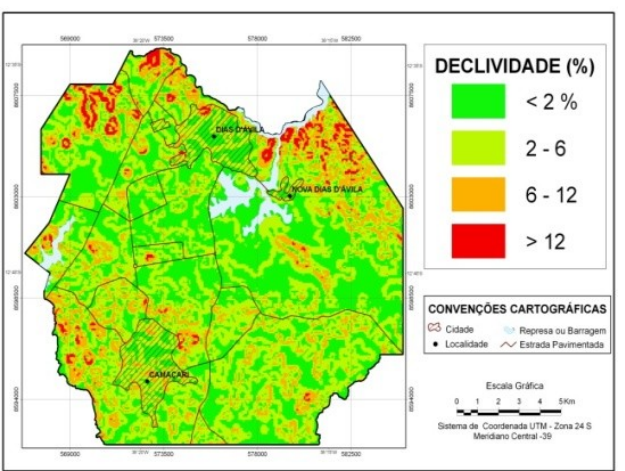

T: Topografia (PESO 1)

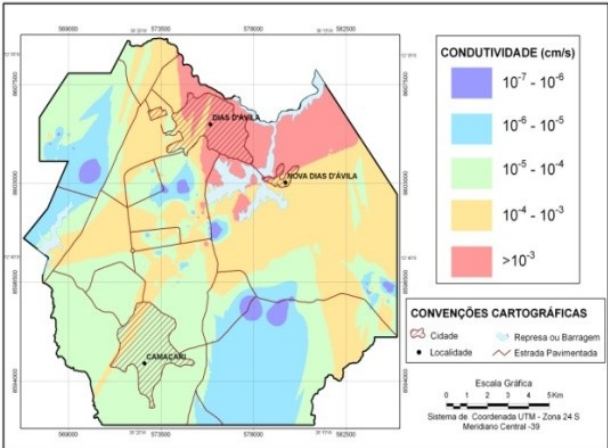

C: Condutividade hidráulica (PESO 3)

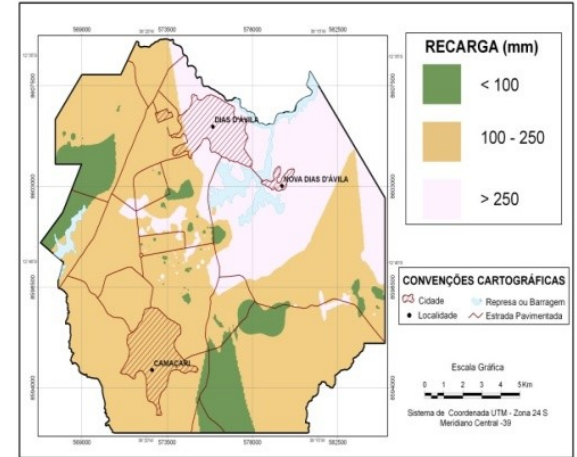

R: Recarga (PESO 4)

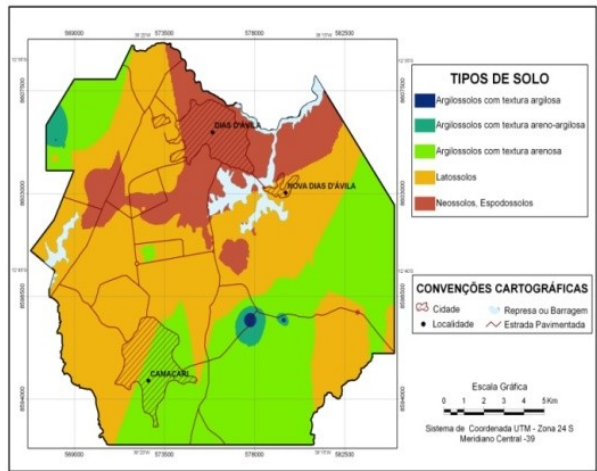

S: Tipo de solo (PESO 2)

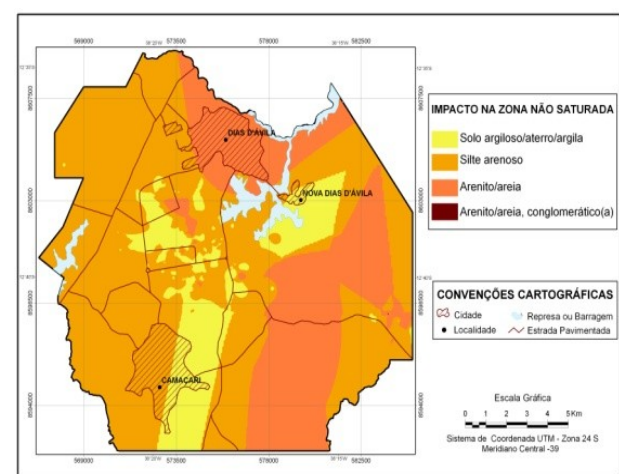

I: Influência da zona não saturada (PESO 5)

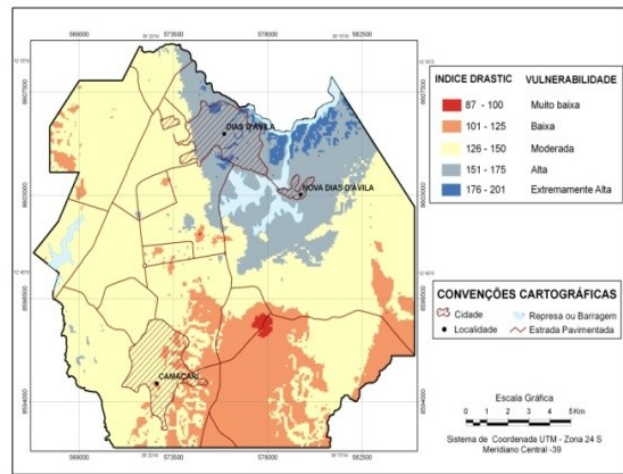

ÍNDICE DRASTIC

Figura 17 - Os sete mapas temáticos e o mapa de Vulnerabilidade DRASTIC. 
Comparando a configuração dos mapas temáticos com o mapa do Índice DRASTIC (Figura 17), verifica-se a maior influência dos temas de peso 5,4 e 3 , sobre o cálculo do índice, respectivamente, profundidade do nível estático (D), influência da zona não saturada (I) a recarga (R) e condutividade hidráulica $(\mathbf{C})$.

Nas áreas de vulnerabilidade extremamente alta a alta $(19,8 \%)$, os parâmetros que mais contribuem para esta vulnerabilidade alta são: a baixa profundidade do nível estático (D), uma zona não saturada arenosa (I), a alta recarga da área $(\mathbf{R})$ e a alta condutividade hidráulica (C).

Portanto, a comparação entre os sete mapas temáticos e o mapa de vulnerabilidade DRASTIC, construído com o somatório dos parâmetros, atesta a capacidade do índice representar a vulnerabilidade do aquífero Marizal na região do Polo Industrial de Camaçari.

\section{CONCLUSÕES}

O cálculo da vulnerabilidade do aquífero Marizal, utilizando o Índice DRASTIC, classificou as áreas do Polo Industrial de Camaçari da seguinte forma: $61,7 \%$ com vulnerabilidade moderada à poluição (áreas com ocupação do solo principalmente destinadas às atividades industriais); 19,8\% com vulnerabilidade de extremamente alta a alta (porção norte, na região da planície de inundação do rio Imbassaí, área de descarga do aquífero freático subjacente ao PIC, e área urbana de Nova Dias Ávila); e 18,5\% com vulnerabilidade entre baixa a muito baixa (área urbana de Camaçari).

O levantamento dos parâmetros, para o cálculo do índice DRASTIC e elaboração do mapa de vulnerabilidade da região do PIC, permitiu identificar o risco potencial de poluição. As fontes potenciais de poluição, principalmente associadas às atividades do PIC, como plantas industriais, áreas de disposição de resíduos, tubovias, sistemas de transporte de efluentes orgânicos e inorgânicos, e outras associadas às estruturas urbanas (cemitérios, postos de gasolinas, hospitais) de Camaçari e Dias D'Ávila ratificam a importância de validação do método DRASTIC na área.

O índice DRASTIC é uma ferramenta útil para a elaboração do mapa de vulnerabilidade com vista ao planejamento e gestão da ocupação do solo de áreas historicamente ocupadas com atividades industriais, urbanas ou rurais, com ou sem passivos ambientais, permitindo aperfeiçoar as ações de proteção e preservação das águas subterrâneas e dos aquíferos da formação Marizal na região do Polo Industrial de Camaçari.

Entretanto, ainda há lacunas importantes no conhecimento da vulnerabilidade natural do aquífero Marizal na região do PIC devidas a vários fatores, como: baixa concentração dos poços da rede de monitoramento em algumas áreas; insuficiente instrumentalização para o cálculo de recarga do aquífero, ausência de detalhamento geológico da área; necessidade de adensamento nas medidas, principalmente de condutividade hidráulica; além do que, neste trabalho somente foram considerados os dados hidrológicos do período de verão de 2006.

Em função da baixa densidade de poços de monitoramento em algumas áreas, principalmente na região de baixa vulnerabilidade, novos estudos mais específicos para melhorar a representatividade e reduzir as incertezas na avaliação do índice de vulnerabilidade devem ser feitos. Melhores informações sobre as características hidrogeológicas, climáticas, tipo de vegetação, e fatores antrópicos como histórico do uso e ocupação do solo, grau de impermeabilização do solo e a qualidade atual das águas subterrâneas, são importantes tanto na avaliação da vulnerabilidade intrínseca quanto na vulnerabilidade específica da área.

Os parâmetros mais sensíveis na área do PIC, principalmente recarga e profundidade do NE, precisam ser avaliados para o período de inverno (maior pluviosidade) para reduzir as subjetividades e refinar a identificação de zonas mais vulneráveis, informações necessárias à consolidação do mapa de vulnerabilidade.

Para as novas explorações de águas subterrâneas através de poços tubulares, as concessões de outorga de uso da água devem ser condicionadas à análise do mapa de vulnerabilidade da região e ao zoneamento dos perímetros de proteção dos poços de produção, antigos e novos, levando em conta também a localização das fontes de contaminação potencial e os passivos ambientais existentes.

Merece resaltar cuidados especiais quanto ao uso do solo urbano de Nova Dias D'Ávila, localizada em área de alta vulnerabilidade, em especial quanto aos seus esgotamentos sanitários, postos de combustíveis e outras atividades potencialmente poluidoras.

\section{AGRADECIMENTOS}

Os autores agradecem ao TECLIM/UFBA e, em especial à CETREL pela cessão de uso dos dados hidrogeológicos da área do Polo Industrial de Camaçari. 


\section{REFERÊNCIAS}

ALBINET, M. \& MARGAT, J. Cartographie de la vulnerabilite a la pollution des nappes d'eau souterraine. Bull BRGM 2me Series, v. 3, n.4, p.13-22, 1970.

ALLER, L.; BENNET, T.; LEHR, J.H. AND PETTY, R. J. DRASTIC. A standardized system for evaluating groundwater pollution potential using hydrogeological setting. US-EPA Report 600/2-85/018; 1987.

CETREL Proteção ambiental: relatório do gerenciamento dos recursos hídricos da região de influência do pólo industrial de Camaçari, período 2006. 2007, 225p. (Relatório interno)

CPRM - Companhia de Pesquisa Mineral. Projeto materiais de construção na região metropolitana de Salvador. Salvador, BA, 2008.

EMPRESA BRASILEIRA DE PESQUISA AGROPECUÁRIA (EMBRAPA). Solos do nordeste. Recife, PE: Embrapa, 2006. Disponível em: <www.uep.cnps.embrapa.br>. Acesso em: nov. 2009.

ESRI . ArcGis (version 9.3) Manual. New York St.: Redlands 2006.

FOSTER, S.S.D. Fundamental Concepts in Aquifer Vulnerability, pollution Risk and Protection Strategy, In: VAN DUIJVANBOODE, W.; VAN WAEGENINGH, H.G. (Eds). THE INTERNATIONAL CONFERENCE HELD IN THE NETHERLANDS, 1987, 38. Proceedings and information. Netherlands: TNO Committee on Hydrological Research, 1987.

FOSTER, S. S. D. \& HIRATA, R. C. A. Groundwater pollution risk assessment: a methodology using available data., Lima, Peru: WHO-PAHO/HPE-CEPIS Technical Manual, 1988. 81p.

HIRATA, R. Oito perguntas e oito tentativas de resposta sobre a vulnerabilidade à poluição de aquíferos. In: SEMINARIOTALLER, PROTECCIÓN DE ACUÍFEROS FRENTE A LA CONTAMINACIÓN: METODOLOGÍA, 2001, 1. Anais... Toluca, México, 20-22 de junio, 2001. 14p.

LE GRAND, H. System for evaluating contamination potential for some waste sites. American Water Work Association Journal, v.56, n.8, p. 959-974, 1964.

LIMA, C. C. U. Reconstrução arquitetural da formação marizal (cretáceo inferior) na Bacia do Recôncavo.1991, 67f. Dissertação (Mestrado) - Universidade Federal da Bahia
Instituto de Geociências, Programa de Pesquisa em Geologia e Geofísica, Bahia, 1991.

LIMA, O. A. L. Caracterização hidráulica e padrões de poluição no aquífero Recôncavo na Região de Camaçari. (Tese de Concurso para Professor Titular)-Universidade Federal da Bahia, Salvador, 1999. 123 p.

NASCIMENTO, K. R. F. Estudo isotópico e hidroquímico de aquífero no polo petroquímico da Bahia. 1999. $67 \mathrm{f}$. Dissertação (Mestrado)- Universidade Federal da Bahia, Instituto de Geociências, Programa de Pesquisa em Geologia e Geofísica, 1999.

NOBRE, R. C. M. Avaliação de risco para o uso e proteção de aquíferos: estudo de caso: Região Metropolitana de Maceió. 2006. 296f. Tese (Doutorado)- COPPE/UFRJ, 2006. Disponível em: <www.coc.ufrj.br>. Acesso em: 25 nov. 2008.

RHAMA Consultoria, Pesquisa e Treinamento Ambiental. Gestão dos Recursos Hídricos Superficiais no Polo Industrial de Camaçari. Relatório interno, 2009. 251 p.

SANTOS, P. R. P., NOBRE, M. M. M.; VILELA, G. M. e CARVALHO, D. M. Groundwater management at the camaçari petrochemical complex: an environmentally sustainable strategy, In: INTERNATIONAL SYMPOSIUM ON MANAGEMENT AND OPERATION OF ENVIRONMENTAL CONTROL SYSTEMS IN THE CHEMICAL AND PETROCHEMICAL INDUSTRY. Anais...Salvador, BA, 1998.

STAGLIORIO. Diagnóstico, plano de implementação e uso do anel florestal do polo industrial de Camaçari. [S.1.]: COFIC, abr. 2005. 824 p.

UNITED STATES ENVIRONMENTAL PROTECTION AGENCY (USEPA). Surface impoundment assessment national report. EPA-570/9-84-002, 200p. 1983.

VIANA, C. F.; E. G. da GAMA JUNIOR; I. ARAUJO SIMÕES; J. A. MOURA; J. REIS FONSECA; R. J. ALVES. Revisão estratigráfica da Bacia Recôncavo/Tucano. Boletim Técnico da Petrobrás, v.14, n. 3, p. 157-192, 1971.

WATERLOO do Brasil. Zoneamento dos recursos hídricos subterrâneos na Região do Polo Petroquímico de Camaçari. Bahia: Cetrel, 2003, 109 p. (Relatório Interno). 